\title{
An engineered PD-1-based and MMP-2/9-oriented fusion protein exerts potent antitumor effects against melanoma
}

\author{
Mulan Wei ${ }^{1,3}$, Xujie Liư ${ }^{2}$, Chunyu Cao ${ }^{1}$, Jianlin Yang ${ }^{1}$, Yafeng $\mathrm{Lv}^{1}$, Jiaojiao Huang ${ }^{1}$, Yanlin $\mathrm{Wang}^{1} \mathcal{E} \mathrm{Ye} \mathrm{Qin}^{1, *}$ \\ ${ }^{1}$ Hubei Key Laboratory of Tumor Microenvironment and Immunotherapy, Three Gorges University Medical College, Yichang, Hubei \\ 443000, ${ }^{2}$ Institute of Medicinal Biotechnology, Chinese Academy of Medical Sciences and Peking Union Medical College, Beijing 100050, \\ ${ }^{3}$ Department of Pathology, Yiling Hospital Yichang, Yichang, Hubei 443100, China
}

Recent studies showed that the PD-1/PD-L1 checkpoint blockade is a dramatic therapy for melanoma by enhancing antitumor immune activity. Currently, major strategies for the PD-1/PD-L1 blockade have mainly focused on the use of antibodies and compounds. Seeking an alternative approach, others employ endogenous proteins as blocking agents. The extracellular domain of PD-1 (ePD1) includes the binding site with PD-L1. Accordingly, we constructed a PD-1-based recombinantly tailored fusion protein (dFv-ePD1) that consists of bivalent variable fragments ( $\mathrm{dFv}$ ) of an MMP-2/9-targeted antibody and ePD1. The melanoma-binding intensity and antitumor activity were also investigated. We found the intense and selective binding capability of the protein dFv-ePD1 to human melanoma specimens was confirmed by a tissue microarray. In addition, dFv-ePD1 significantly suppressed the migration and invasion of mouse melanoma B16-F1 cells, and displayed cytotoxicity to cancer cells in vitro. Notably, dFv-ePD1 significantly inhibited the growth of mouse melanoma B16-F1 tumor cells in mice and in vivo fluorescence imaging showed that dFv-ePD was gradually accumulated into the B16-F1 tumor. Also the B16-F1 tumor fluorescence intensity at the tumor site was stronger than that of $\mathrm{dFv}$. This study indicates that the recombinant protein $\mathrm{dFv}$-ePD1 has an intensive melanoma-binding capability and exerts potent therapeutic efficacy against melanoma. The novel format of the PD-L1-blocked agent may play an active role in antitumor immunotherapy. [BMB Reports 2018; 51(11): 572-577]

*Corresponding author. Tel: +86-0717-6397179; Fax: +86-07176397328; E-mail: ycqinye@163.com

https://doi.org/10.5483/BMBRep.2018.51.11.076

Received 10 April 2018, Revised 24 April 2018, Accepted 11 June 2018

Keywords: Antitumor efficacy, Melanoma, MMP-2/9, PD-1/PD-L1, Targeting protein

\section{INTRODUCTION}

A dynamic interplay exists between hosts and tumors, and the ability of the tumor to evade immune recognition often determines the clinical course of the disease. Tumors express antigens that can be recognized by host $T$ cells, but full clearance of tumors by the immune system alone is rare. Part of this failure is due to immune suppression in the tumor microenvironment. An important role of the tumor's microenvironment is covered by the programmed cell death-1 (PD-1)/programmed cell death-ligand 1 (PD-L1) axis (1). PD-1 is an immunosuppression receptor mainly expressed on the surface of activated T cells, as well as other immune cells (2, 3). Recent research shows PD-L1, the ligand of PD-1, is expressed on a wide variety of solid tumors, including breast, lung, colon, ovarian cancer, and melanoma (4-8). Binding of PD-1 with PD-L1 can inhibit a T cell-mediated immune response and contribute to tumor immune evasion $(9,10)$. This potential mechanism of immune resistance in tumor tissues suggests that the treatment directed at blocking the interaction between PD-1 and PD-L1 might enhance endogenous antitumor immunity.

Currently, immunomodulatory agents as a new immunotherapeutic strategy are used for cancer therapy in many recent studies (11). The anti-PD-1 or anti-PD-L1 strategy can be effective in several solid tumors such as renal cell carcinoma (RCC), non-small cell lung cancer (NSCLC), and melanoma (12-14). Research shows that the expression of PD-L1 is increased on BRAF-mutated melanoma cells as cells resistant to BRAF or MEK inhibitors. This contributes to more aggressive behavior of melanoma (15). The abnormally high expression of PD-L1 in melanoma tissues is not only used in the prognosis of cancer patients, but also is becoming an effective molecular target of cancer therapy $(16,17)$. A variety of drugs targeting the PD-1/PD-L1 signaling pathway were developed for preclinical research and clinical treatment of tumors. Compared with investigator-choice chemotherapy, the anti-PD-1 antibodies Nivolumab and Pembrolizumab increased patients' objective response and overall survival significantly in clinical trials $(18,19)$. However, the inability to target leading to toxicity and immune-related toxicities of the PD-1/PD-L1-

ISSN: 1976-670X (electronic edition)

Copyright (c) 2018 by the The Korean Society for Biochemistry and Molecular Biology

(c) This is an open-access article distributed under the terms of the Creative Commons Attribution Non-Commercial License (http://creativecommons.org/licenses/by-nc/4.0) which permits unrestricted non-commercial use, distribution, and reproduction in any medium, provided the original work is properly cited. 
blocked agents limit their clinical application (20).

The matrix metalloproteinase (MMP) family as a type of specific proteolytic enzyme is of great concern in recent years. It is abundantly expressed and secreted in various tumor tissues and plays an important role in the degradation of the tumor extracellular matrix (21). Type IV collagenase (also known as gelatinase) is a type of matrix metalloproteinase, including MMP-2 and MMP-9. The abundant expression of gelatinases in destroying the integrity of the basement membrane and extracellular matrix can promote tumor growth, invasion and metastasis, and participate in tumor angiogenesis $(22,23)$. Furthermore, the expression of gelatinases is considered as an important biomarker and correlates highly with the poor outcome of cancer therapy (24-27). Therefore, it is feasible to employ anti-gelatinase agents as a targeted drug carrier. It is known that single-chain variable fragments $(\mathrm{scFv})$ are considered the most frequently used and the most favored fragment to deliver protein-based drugs to cancer cells because of their moderate molecular size and faster tissue penetration (28). A monoclonal antibody $(\mathrm{mAb}) 3 \mathrm{G} 11$ was produced using gelatinases as the antigen, and employed as a carrier for targeted delivery of Lidamycin (29-31). Moreover, the bivalent variable fragment $(\mathrm{dFv})$ of 3G11 showed the ideal targeting effect and tumor suppression compared to the monovalent format (scFv) $(32,33)$. The high expression of MMP-2/9 is closely related to tumor formation, development, invasion, metastasis, and poor prognosis. So, MMP-2/9-targeted inhibition is becoming a new approach to treat metastatic tumors $(34,35)$.

In the present study, we generated the fusion protein $\mathrm{dFv}$-ePD1, which combined an MMP-2/9-targeted dFv and an extracellular domain of PD-1 (ePD1). Exogenous ePD1 including the binding site with PD-L1 can be used to bind PD-L1 on the surface of cancer cells and block the interaction with immune cells. Melanoma cells and tissues were used to evaluate the affinity of $\mathrm{dFv}$-ePD1 fusion protein and its ability to inhibit tumor invasion and metastasis. The therapeutic efficacy of dFv-ePD1 was evaluated using mouse melanoma B16-F1 cells as a model. The study provides evidence that dFv-ePD1 shows potent antitumor efficacy in vitro and in vivo.

\section{RESULTS}

\section{Construction of the dFv-ePD1 and dFv pro35 karyotic expression plasmid}

As shown in Fig. 1A, the recombinant plasmid pET30a $(+) /$ dFv-ePD1 was obtained by genetic engineering. The DNA fragment encoding for protein $\mathrm{dFv}$ was cloned from Plasmid $\mathrm{pET30a}(+) / \mathrm{dFv}$-LDP and inserted into the Ndel/HindIII restriction sites of the expression plasmid $\mathrm{pET30a}(+)$ to generate the plasmid $\mathrm{pET}-30 \mathrm{a}(+) / \mathrm{dFv}$. The DNA fragment (501 bp) encoding for ePD1 was copied from cDNA of mice spleen cells (Fig. 1B). Subsequently, ePD1 was inserted into the HindIII/Xhol restriction sites of expression plasmid
$\mathrm{pET} 30 \mathrm{a}(+) / \mathrm{dFv}$ to generate the plasmid pET-30a(+)/dFv-ePD1 (Fig. 1A). The recombinant plasmid was verified using enzyme digestion (Fig. 1C). And DNA sequencing confirmed that the correct DNA fragments were inserted.

\section{Preparation and identification of the fusion protein}

The engineered protein dFv-ePD1 was successfully expressed after the plasmid $\mathrm{pET} 30 \mathrm{a}(+) / \mathrm{dFv}-\mathrm{ePD} 1$ was transfected into $E$.

A.

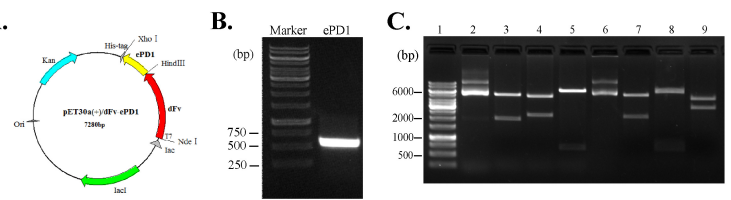

D.
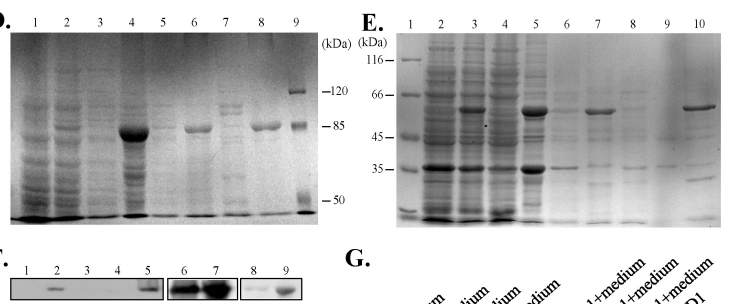

G.

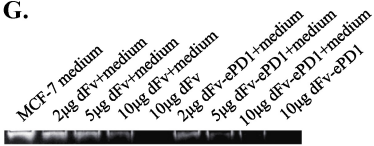

Fig. 1. Construction and expression of fusion gene dFv-ePD1 and dFv. (A) Sketch map of the pET30a $(+) / d F v-e P D 1$ recombinant plasmid. (B) ePD1 fragment was amplified by RT-PCR. (C) Verification of plasmids by enzyme digestion. 1, DNA marker; 2 , recombinant plasmid pET30a(+)/dFv-ePD1; 3, 4 and 5, pET30a $(+) /$ dFv-ePD1 plasmid digested with Ndel/Xhol, HindIII/Mlul and $\mathrm{Ndel} / E \mathrm{EcoRl}$; Lane 6, recombinant plasmid $\mathrm{pET} 30 \mathrm{a}(+) / \mathrm{dFv} ; 7,8$ and $9, \quad \mathrm{pET} 30 \mathrm{a}(+) / \mathrm{dFv}$ recombinant plasmid digested with $\mathrm{Ndel} / \mathrm{Hind}$ III, EcoRI/HindIII and HindIII/Mlul, respectively. (D) Expression analysis of fusion protein dFv-ePD1. 1), total proteins before IPTG induction; 2), total proteins after IPTG induction; 3), the soluble portion of the cell lysate in binding buffer I; 4), the inclusion bodies; 5), the soluble portion of the cell lysate in binding buffer II; 6), the soluble portion of the cell lysate in binding buffer III; 7), proteins unbound with an $\mathrm{Ni}^{2+}$ column; 8), the purified dFv-ePD1 using an $\mathrm{Ni}^{2+}$ column; 9), protein marker $(\mathrm{kDa})$; (E) Expression analysis of fusion protein $\mathrm{dFv} .1)$, protein marker $(\mathrm{kDa})$; 2 ), total proteins before IPTG induction; 3), total proteins after IPTG induction; 4), the soluble portion of the cell lysate in binding buffer I; 5), the inclusion bodies; 6), the soluble portion of the cell lysate in binding buffer II; 7), the soluble portion of the cell lysate in binding buffer III; 8), proteins unbound with an $\mathrm{Ni}^{2+}$ column; 9), proteins washed with a washing buffer; 10), the purified $\mathrm{dFv}$ using an $\mathrm{Ni}^{2+}$ column ; (F) Characterization of dFv-ePD1 by Western blotting. 1), total proteins before IPTG induction; 2), total proteins after IPTG induction; 3), cultural supernatants; 4), the soluble portion of the cell lysate in binding buffer I; 5), the inclusion bodies; 6) and 7), the purified dFv-ePD1 and the renatured dFv-ePD1 detected with anti-His tag $\mathrm{mAb}$, respectively; 8) and 9), the purified dFv-ePD1 and the renatured dFv-ePD1 detected with anti-PD-1 antibody, respectively. (G) The inhibitory effect of different concentrations of $\mathrm{dFv}$ and dFv-ePD1 on gelatinase using Reverse Zymography analysis. 
coli Transetta (DE3). As shown in Fig. 1D, the total proteins after IPTG induction (Lane 2) have the band of the fusion protein $\mathrm{dFv}$-ePD1 (85 $\mathrm{kDa}$ ) compared to the ones before IPTG induction (Lane 1). The fusion proteins were accumulated in intracellular inclusion bodies (Lane 4). The band of protein $\mathrm{dFv}$ was showed at the site of $55 \mathrm{kDa}$ (Fig. 1E). The inclusion bodies were treated with $2 \mathrm{~mol} / \mathrm{L}$ and $6 \mathrm{~mol} / \mathrm{L}$ urea. As shown in Lane 6 of Fig. 1D, the fusion protein was more soluble in a binding buffer III (6 mol/L urea). As shown in the results of an SDS-PAGE and a Western blotting, the purity of dFv-ePD1 treated with a $\mathrm{Ni}^{2+}$ column was over $90 \%$ (Fig. 1D, 1F). The reverse Zymography assay was used to measure the activity of the renatured fusion protein. The results showed that both the renatured proteins $\mathrm{dFv}$ and $\mathrm{dFv}$-ePD1 had an inhibitory effect on gelatinase depending on their concentration (Fig. 1G). The results indicated that the $\mathrm{dFv}-\mathrm{ePD} 1$ and $\mathrm{dFv}$ were successfully purified and renatured.

\section{Binding affinity of dFv-ePD1 with cancer cells and tumor tissue}

The binding capability of $\mathrm{dFv}$-ePD1 to B16-F1 cells was examined by immunofluorescence (Fig. 2A) and flow cytometry (Fig. 2B). The results showed that dFv-ePD1 could
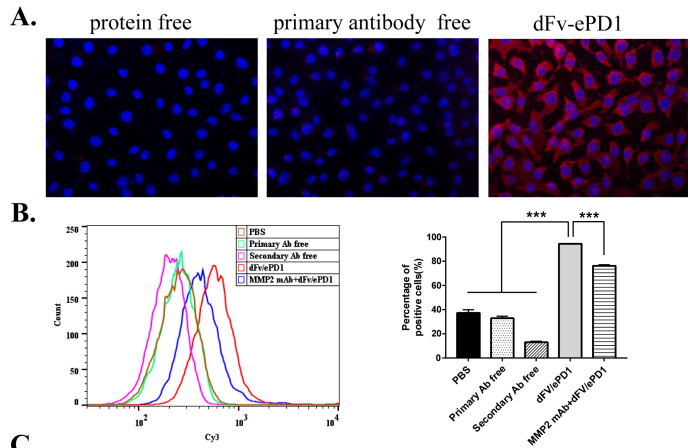

C.
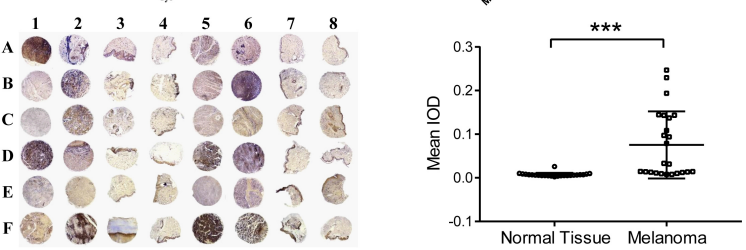

Fig. 2. Fusion proteins dFv-ePD1 have potent binding abilities to binding with B16-F1 cells and human melanoma tissue. (A) The binding affinity of $200 \mu \mathrm{g} / \mathrm{ml} \mathrm{dFv-ePD1}$ protein with B16-F1 cells analyzed by immunofluorescence staining $(\times 40)$. The red color represents $\mathrm{dFv}$-ePD1; blue color indicates the nuclei. (B) Binding affinity of $200 \mu \mathrm{g} / \mathrm{ml}$ dFv-ePD1 with the B16-F1 cells analyzed by flow cytometry. (C) The binding ability of $80 \mu \mathrm{g} / \mathrm{ml} \mathrm{dFv}$-ePD1 to human melanoma tissue. Columns 1, 2, 5, and 6 are human melanoma tissues and columns $3,4,7$, and 8 are human normal skin tissues. The right figure is the mean cumulative optical density value of human melanoma and human normal skin tissue, $* * * P<0.001$. bind to the B16-F1 cells, and this effect could be blocked by an anti-MMP2 specific antibody (Fig. 2B). Tissue microarray of human melanoma and normal skin tissue was applied to further confirm the that dFv-ePD1 could bind to human melanoma specimens. The scanning pattern in the image of the immunohistochemistry results in each case of the microarray is presented in Fig. 2C. The mean cumulative value of the optical density of the human melanoma tissue group was significantly higher than that of the normal skin tissue group ( $\mathrm{P}<0.001)$. Evidently, this indicates that the fusion protein $\mathrm{dFv}$-ePD1 prefers to bind to human melanoma tissue compared to normal skin tissue.

\section{Inhibitory effect of dFv-ePD1 on migration, invasion and cell} growth of melanoma B16-F1 cells in vitro

We observed the role of dFv-ePD1 in B16-F1 cancer cell migration and invasion. As shown in Fig. $3 \mathrm{~A}$ and $3 \mathrm{~B}$, both dFv-ePD1 and dFv inhibited the migration and invasion of B16-F1 cells. Furthermore, the inhibitory effects of fusion protein $\mathrm{dFv}$-ePD1 were more than that of dFv. Using the MTT assay, fusion protein dFv-ePD1 significantly inhibited the proliferation of mouse melanoma cells B16-F1 and human non-small cell lung cancer cells A549. Fused protein $\mathrm{dFv}$-ePD1 showed moderate inhibition of the proliferation of human cervical cancer cells HeLa and human ovarian cancer cells SKOV-3 cells. Protein dFv did not show significant inhibition to proliferation of tumor cells in vitro (Fig. 3C).
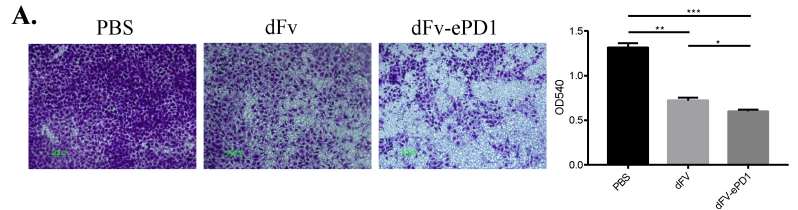

B.

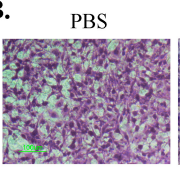

$\mathrm{dFv}$ dFv-ePD1
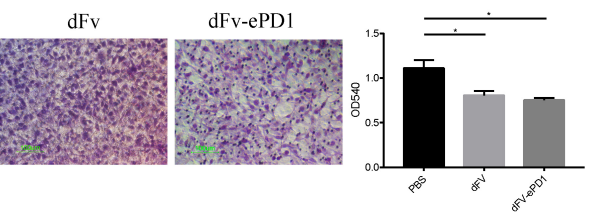

C.

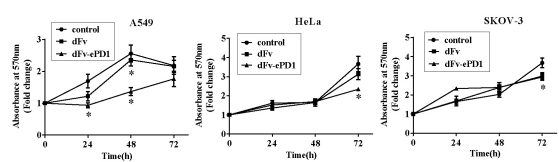

Fig. 3. Fusion protein $\mathrm{dFv}-\mathrm{ePD} 1$ inhibited the growth, migration and invasion of B16-F1 cells in vitro. (A) The effect of $100 \mu \mathrm{g} / \mathrm{ml}$ dFv-ePD1 on the migration of B16-F1 cells was measured by a transwell migration assay. (B) The invasive abilities of B16-F1 cells were determined in a Boyden chamber assay after treatment with $100 \mu \mathrm{g} / \mathrm{ml}$ protein $\mathrm{dFv}$-ePD1 and $\mathrm{dFv}$, respectively. The right figures indicate absorbance at $540 \mathrm{~nm}$. $* \mathrm{P}<0.05 * * \mathrm{P}<0.01$ $* * * \mathrm{P}<0.001$. (C) Proliferation inhibition of B16-F1, A549, HeLa, and SKOV-3 cancer cells by dFv-ePD1(50 $\mu \mathrm{g} / \mathrm{ml})$ determined by the MTT assay at 24,48 , and 72 hours, respectively. ${ }^{* P}<0.05$. 


\section{In vivo imaging of fusion proteins}

C57BL6J mice bearing B16 melanoma models were used for the study of tumor accumulation of DyLight 680 labeled dFv and dFv-ePD1 (Fig. 4A) (36). The variations in fluorescence intensity at the tumor region were monitored for 24 hours. As shown in Fig. 5, the fluorescence intensity of both proteins in the tumor location increased gradually with time during the period 2 hours after the injections. The dFv-ePD1 showed stronger fluorescence intensity compared to $\mathrm{dFv}$ at the same observation times. This observation provides evidence that dFv-ePD1 can accumulate in B16 melanoma and have better or quicker targeting activity than $\mathrm{dFv}$.

\section{In vivo therapeutic efficacy of fusion protein $\mathrm{dFv}$-ePD1}

Mouse melanoma B16-F1 cells were transplanted subcutaneously into the flank of C57BL/6 mice at day 0 . At day 11 , the experimental mice were divided into 3 groups. The three groups were PBS, $\mathrm{dFv}$ and $\mathrm{dFv}$-ePD1. At day 11 and day 17, PBS, $20 \mathrm{mg} / \mathrm{kg} \mathrm{dFv}$ and $20 \mathrm{mg} / \mathrm{kg} \mathrm{dFv}$-ePD1 were injected intraperitoneally, respectively. The results showed that both $\mathrm{dFv}$ and dFv-ePD1 inhibited the growth of the tumor (Fig. 4B), and the prepared $\mathrm{dFv}$-ePD1 exhibited significantly enhanced therapeutic effects on B16-F1 xenograft as compared with $\mathrm{dFv}$ $(50.9 \%$ versus $32.4 \%, \mathrm{P}<0.01)$.

\section{DISCUSSION}

Currently, the development of immune-modulating agents has

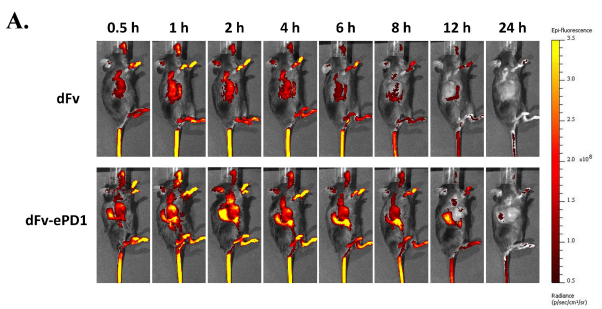

B.

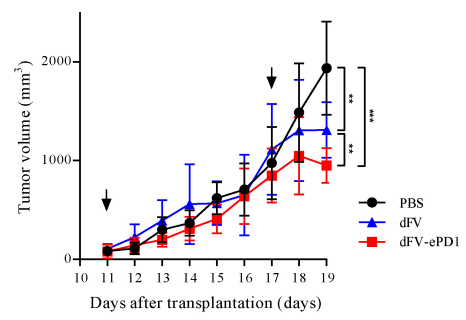

Fig. 4. In vivo tumor targeting and therapeutic efficacy of fusion protein. (A) In vivo optical imaging in B16 melanoma-bearing C57BL/6J mice using DyLight680-labeled dFv and dFv-ePD1. Representative in vivo flurescence images at a series of points in time observed after tail vein injection of $20 \mathrm{mg} / \mathrm{kg} \mathrm{dFv}$ or dFv-ePD1. Color scale represents photons $/ \mathrm{sec} / \mathrm{cm}^{2} /$ steradian. (B) The growth inhibition of $\mathrm{dFv}$ and $\mathrm{dFv}$-ePD1 on mouse melanoma B16-F1. ${ }^{* * P}<0.01{ }^{* * * P}<0.001$. significantly improved the survival for patients with malignancy. Clinical trials with anti-CTLA-4, anti-PD-1, and anti-PD-L1 agents have shown objective clinical activity in melanoma, NSCLC, bladder, and other cancers. Research with anti PD-1/PD-L1 agents have shown higher response rates than that using anti-CTLA-4 (37). Tumor cells exploit the immunecheckpoint PD-1/PD-L1 pathway as a mechanism to evade detection and inhibit the immune response. The deactivated $\mathrm{T}$ cells are kept inhibited by interacting with tumor cells in the tumor microenvironment, which possibly provides a way to reactivate them to kill tumor cells. Due to expression on the tumor cells, targeting PD-L1 may theoretically offer benefits above those of PD-1.

As the ligand of PD-1, PD-L1 can bind to particularly to the extracellular portion of PD-1. Through binding to PD-L1, PD-1 transmits an inhibitory signal to the $\mathrm{T}$ cell, which reduces cytokine production and suppresses T-cell proliferation. If the binding site of PD-L1 is occupied by a free extracellular portion of PD-1, it cannot bind to the PD-1 portion expressed on $\mathrm{T}$ cells. Therefore, we choose the ePD-1 as a PD-L1-blocked agent to check its effect on tumor growth. There were several recent papers that reported that cell-intrinsic PD-L1 proteins regulate the cell growth through PI3K/AKT pathway activation (38-40). Our fusion protein containing a PD-1 extracellular domain could bind to the cell membrane of PD-L1 to block a PD-L1/PD-1 interaction. It could then inactivate the intrinsic cell growth signal of cancer cells. However, PD-L1 is expressed not only in cancer cells, but also in a variety of normal hematopoietic and nonhematopoietic cells. The non-targeting and immune-related toxicities were reported in many studies for PD-L1-blocked agents. Tumor-targeted delivery of a PD-L1-blocked agent is a way to reduce the effects of interactions with non-targeted molecules.

Gelatinase (including MMP-2/9) plays an important role in tumor growth and metastasis; overexpression of these molecules is strongly correlated with a poor prognosis in a variety of cancers. MMP-2/9 is a tumor antigen whose expression is critical for tumor growth or invasiveness in melanoma $(41,42)$. MMP-2-specific $\mathrm{CD}^{+} \mathrm{T}$ lymphocytes display an inflammatory $\mathrm{T}_{\mathrm{H}} 2$ profile, and MMP-2-conditioned dendritic cells prime $\mathrm{T}_{\mathrm{H}} 2$ responses against several melanomaassociated antigens (41). Therefore, gelatinases are a possible target for cancer therapy and immunotherapy. In this article, we prepared and identified a gelatinases-targeting tandem scFv-based fusion protein (dFv-ePD1) successfully, as one that targets the PD-L1-blocked agent. The dFv-ePD1 shows potent binding capability to B16-F1 cells and human melanoma tissue microarray via the interaction of the $\mathrm{dFv}$ moiety with gelatinases and the ePD1 binds to PD-L1 as well. The fusion protein $\mathrm{dFv}$-ePD1 can gather to the tumor site in the mouse model because of the targeting ability of $\mathrm{dFv}$. Meanwhile, dFv-ePD1 shows more accumulation to tumor tissues than $\mathrm{dFv}$. We speculate that ePD1 also has the effect of targeting 
the tumor due to the binding ability of PD-L1, which is overexpressed by melanoma.

Our results demonstrate that the fusion protein $\mathrm{dFv}$-ePD1 retains the activity of $\mathrm{dFv}$ that likely inhibits the activity of gelatinase. Meanwhile, we observed that the fusion protein dFv-ePD1 displayed more potent inhibitory effects on the migration and invasion of B16-F1 cells compared with dFv. The fusion protein $\mathrm{dFv}-\mathrm{ePD} 1 \mathrm{can}$ inhibit the proliferation and growth of mouse melanoma B16-F1 cells significantly in vitro and in vivo.

Taken together, we generated a tandem scFv-based and PD-1 extracellular domain integrated fusion protein that targets gelatinases. Compared to Fv or ePD-1 alone, this fusion protein could target the tumor tissue through the gelatinasestargeting binding activity of $\mathrm{dFv}$ to disrupt the tumor microenvironment. And the fusion protein could also block the immunosuppressive signal PD-1/PD-L1 through ePD-1, which is delivered by $\mathrm{dFv}$ in tumors to enhance the immune response. The fusion proteins are highly relevant to cancer invasion, metastasis and cancer cell-stromal cell interactions. The fusion protein has the activity of targeting melanoma cells in vitro and in vivo, and inhibiting the proliferation, migration, and invasion of melanoma cells; with potential clinical applications in the treatment of melanoma.

\section{MATERIALS AND METHODS}

Detailed information is in the Supplementary Material.

\section{ACKNOWLEDGEMENTS}

We appreciate Prof. Yongsu Zhen from Chinese Academy of Medical Sciences and Peking Union Medical College who provided the plasmid pET30a $(+) / \mathrm{dFv}$-LDP. This work was supported by the grants from National Natural Science Foundation of China (81502366) for Ye Qin and National Natural Science Foundation of China (81772833) for Chunyu Cao.

\section{CONFLICTS OF INTEREST}

The authors have no conflicting interests.

\section{REFERENCES}

1. Ostrand-Rosenberg S, Horn LA and Haile ST (2014) The programmed death-1 immune-suppressive pathway: barrier to antitumor immunity. J Immunol 193, 3835-3841

2. Simon S and Labarriere N (2017) PD-1 expression on tumor-specific T cells: Friend or foe for immunotherapy? Oncoimmunology 7, e1364828

3. van de Ven R, Niemeijer AN, Stam AGM et al (2017) High PD-1 expression on regulatory and effector T-cells in lung cancer draining lymph nodes. ERJ Open Res 3, 1-9

4. Mittendorf EA, Philips AV, Meric-Bernstam F et al (2014)
PD-L1 expression in triple-negative breast cancer. Cancer Immunol Res 2, 361-370

5. Brody R, Zhang Y, Ballas M et al (2017) PD-L1 expression in advanced NSCLC: Insights into risk stratification and treatment selection from a systematic literature review. Lung Cancer 112, 200-215

6. Masugi Y, Nishihara R, Yang J et al (2017) Tumour CD274 (PD-L1) expression and T cells in colorectal cancer. Gut 66, 1463-1473

7. Howitt BE, Strickland KC, Sholl LM et al (2017) Clear cell ovarian cancers with microsatellite instability: A unique subset of ovarian cancers with increased tumor-infiltrating lymphocytes and PD-1/PD-L1 expression. Oncoimmunology 6, e1277308

8. Kaunitz GJ, Cottrell TR, Lilo M et al (2017) Melanoma subtypes demonstrate distinct PD-L1 expression profiles. Lab Invest 97, 1063-1071

9. Chemnitz JM, Parry RV, Nichols KE, June $\mathrm{CH}$ and Riley JL (2004) SHP-1 and SHP-2 associate with immunoreceptor tyrosine-based switch motif of programmed death 1 upon primary human $\mathrm{T}$ cell stimulation, but only receptor ligation prevents $\mathrm{T}$ cell activation. J Immunol 173, 945-954

10. Keir ME, Butte MJ, Freeman GJ and Sharpe AH (2008) PD-1 and its ligands in tolerance and immunity. Annu Rev Immunol 26, 677-704

11. Wolchok JD, Kluger H, Callahan MK et al (2013) Nivolumab plus ipilimumab in advanced melanoma. $\mathrm{N}$ Engl J Med 369, 122-133

12. Topalian SL, Hodi FS, Brahmer JR et al (2012) Safety, activity, and immune correlates of anti-PD-1 antibody in cancer. N Engl J Med 366, 2443-2454

13. Cho DC, Sosman JA, Sznol M et al (2013) Clinical activity, safety, and biomarkers of MPDL3280A, an engineered PD-L1 antibody in patients with metastatic renal cell carcinoma (mRCC). J Clin Oncol 31, 4505-4505

14. Herbst RS, Soria JC, Kowanetz M et al (2014) Predictive correlates of response to the anti-PD-L1 antibody MPDL3280A in cancer patients. Nature 515, 563-567

15. Audrito V, Serra S, Stingi A et al (2017) PD-L1 up-regulation in melanoma increases disease aggressiveness and is mediated through miR-17-5p. Oncotarget 8, 15894-15911

16. Obeid JM, Erdag G, Smolkin ME et al (2016) PD-L1, PD-L2 and PD-1 expression in metastatic melanoma: Correlation with tumor-infiltrating immune cells and clinical outcome. Oncoimmunology 5, e1235107

17. Ribas A and Tumeh PC (2014) The future of cancer therapy: selecting patients likely to respond to PD1/L1 blockade. Clin Cancer Res 20, 4982-4984

18. Ribas A, Puzanov I, Dummer R et al (2015) Pembrolizumab versus investigator-choice chemotherapy for ipilimumab-refractory melanoma (KEYNOTE-002): a randomised, controlled, phase 2 trial. Lancet Oncol 16, 908-918

19. Weber JS, D'Angelo SP, Minor D et al (2015) Nivolumab versus chemotherapy in patients with advanced melanoma who progressed after anti-CTLA-4 treatment (CheckMate 037): a randomised, controlled, open-label, phase 3 trial. Lancet Oncol 16, 375-384 
20. Postow MA, Chesney J, Pavlick AC et al (2015) Nivolumab and ipilimumab versus ipilimumab in untreated melanoma. N Engl J Med 372, 2006-2017

21. Kessenbrock K, Plaks V and Werb Z (2010) Matrix metalloproteinases: regulators of the tumor microenvironment. Cell 141, 52-67

22. Egeblad M and Werb Z (2002) New functions for the matrix metalloproteinases in cancer progression. Nat Rev Cancer 2, 161-174

23. John A and Tuszynski G (2001) The role of matrix metalloproteinases in tumor angiogenesis and tumor metastasis. Pathol Oncol Res 7, 14-23

24. Pellikainen JM, Ropponen KM, Kataja VV, Kellokoski JK, Eskelinen MJ and Kosma VM (2004) Expression of matrix metalloproteinase (MMP)-2 and MMP-9 in breast cancer with a special reference to activator protein-2, HER2, and prognosis. Clin Cancer Res 10, 7621-7628

25. Liu Z, Li L, Yang Z et al (2010) Increased expression of MMP9 is correlated with poor prognosis of nasopharyngeal carcinoma. BMC Cancer 10, 270

26. Karam A and Dorigo O (2012) MMPs in ovarian cancer as therapeutic targets. Anticancer Agents Med Chem 12, 764-772

27. Roy R, Yang J and Moses MA (2009) Matrix metalloproteinases as novel biomarkers and potential therapeutic targets in human cancer. J Clin Oncol 27, 5287-5297

28. Beckman RA, Weiner LM and Davis HM (2007) Antibody constructs in cancer therapy: protein engineering strategies to improve exposure in solid tumors. Cancer 109, 170-179

29. Li L, Huang YH, Li Y, Wang FQ, Shang BY and Zhen YS (2005) Antitumor activity of anti-type IV collagenase monoclonal antibody and its lidamycin conjugate against colon carcinoma. World J Gastroenterol 11, 4478-4483

30. Wang FQ, Shang BY and Zhen YS (2003) [Antitumor effects of the immunoconjugate composed of lidamycin and monoclonal antibody 3G11]. Yao Xue Xue Bao 38, 515-519

31. Qin Y, Liu XJ, Li L et al (2014) MMP-2/9-oriented combinations enhance antitumor efficacy of EGFR/HER2- targeting fusion proteins and gemcitabine. Oncol Rep 32, 121-130

32. Holliger P and Hudson PJ (2005) Engineered antibody fragments and the rise of single domains. Nat Biotechnol $23,1126-1136$

33. Zhong G, Zhang S, Li Y et al (2010) A tandem scFv-based fusion protein and its enediyne-energized analogue show intensified therapeutic efficacy against lung carcinoma xenograft in athymic mice. Cancer Lett 295, 124-133

34. Hidalgo M and Eckhardt SG (2001) Development of matrix metalloproteinase inhibitors in cancer therapy. J Natl Cancer Inst 93, 178-193

35. Zucker S, Cao J and Chen WT (2000) Critical appraisal of the use of matrix metalloproteinase inhibitors in cancer treatment. Oncogene 19, 6642-6650

36. Liu XJ, Li L, Liu XJ et al (2017) Mithramycin-loaded mPEG-PLGA nanoparticles exert potent antitumor efficacy against pancreatic carcinoma. Int J Nanomedicine 12, 5255-5269

37. Vanella V, Festino L, Strudel M, Simeone E, Grimaldi AM and Ascierto PA (2017) PD-L1 inhibitors in the pipeline: Promise and progress. Oncoimmunology 7, e1365209

38. Kleffel S, Posch C, Barthel SR et al (2015) Melanoma cell-intrinsic PD-1 receptor functions promote tumor growth. Cell 162, 1242-1256

39. Clark CA, Gupta HB, Sareddy G et al (2016) Tumor-intrinsic PD-L1 signals regulate cell growth, pathogenesis, and autophagy in ovarian cancer and melanoma. Cancer Res 76, 6964-6974

40. Almozyan S, Colak D, Mansour F et al (2017) PD-L1 promotes OCT4 and Nanog expression in breast cancer stem cells by sustaining PI3K/AKT pathway activation. Int J Cancer 141, 1402-1412

41. Godefroy E, Manches O, Dreno B et al (2011) Matrix metalloproteinase- 2 conditions human dendritic cells to prime inflammatory $\mathrm{T}(\mathrm{H}) 2$ cells via an IL-12- and OX40L-dependent pathway. Cancer Cell 19, 333-346

42. Zhou J, Jin B, Jin Y, Liu Y and Pan J (2017) The antihelminthic drug niclosamide effectively inhibits the malignant phenotypes of uveal melanoma in vitro and in vivo. Theranostics $7,1447-1462$ 